\section{AROUND THE WORLD}

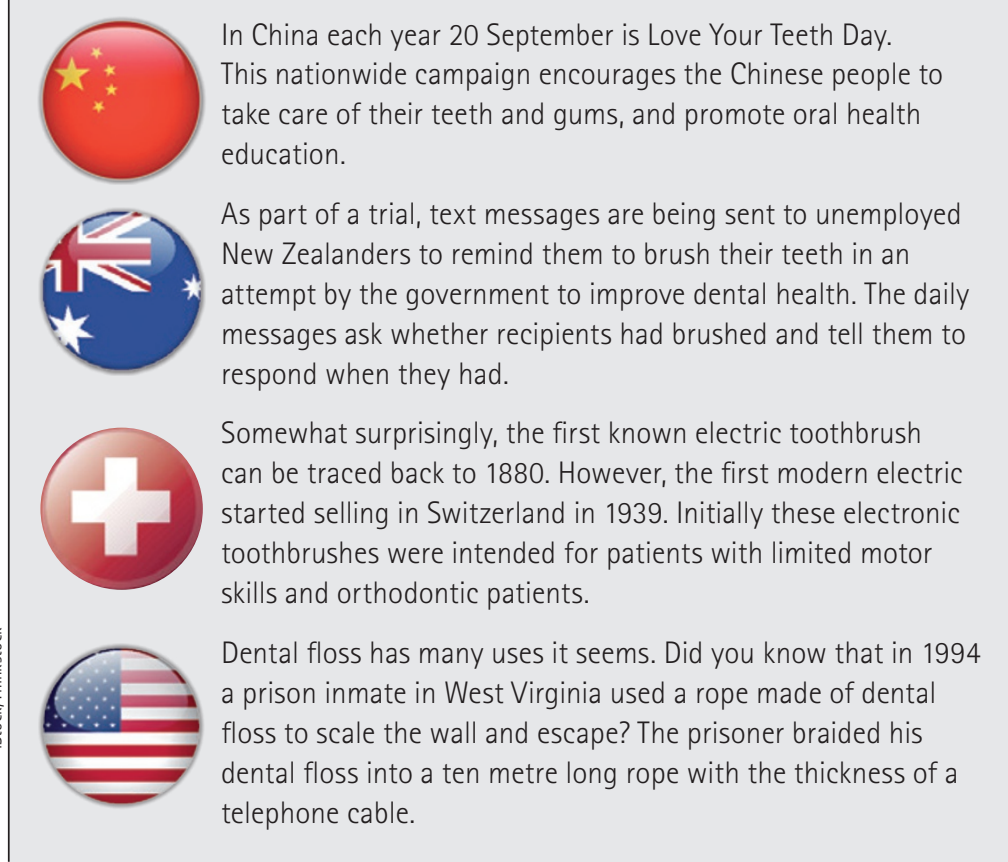

\section{A GOOD YEAR TO FIND WORK}

Around nine out of ten dentists completing their vocational or foundation training in summer 2014 found a post, according to the latest research from the British Dental Association (BDA). On average, the process took about six weeks, with candidates making three applications for every interview they attended.

The research revealed that the 2014 cohort are more likely to stay in the practice in which they had trained than the 2013 cohort and that over half had found a post in general dental practice, compared with around four in ten who had opted for a hospital post.

Findings from the 2014 survey of foundation dentists and vocational dental practitioners are available on the BDA website at: https://www.bda. org/dentists/policy-campaigns/ research/workforce-finance/ students-young/vdp-survey.

\section{JOHN MONTGOMERY GORMAN}

We regret to announce that John Montgomery Gorman MDS FDS FFD died on 18 November 2014.

John, born 12 October 1929, was a consultant in the Northern Ireland Plastic and Maxillo Facial Service. During his time as a Consultant Surgeon the "Northern Ireland Troubles' were taking place and John was deeply involved in the restorative surgery for the unfortunate victims. In addition to his normal work, he undertook the role of lead clinician for Maxillo Facial Surgery, after the retirement of Roy Whitlock in 1983.

John was interested in yachting and rowing and he became captain of the Queen's University Rowing Club in the 1950-1951 season. In 1956 he married Jane and they had three children, Dermot, Lesley and Anne. Sadly, his wife Jane pre-deceased him in the year 2000.

John Gorman was a gentleman respected by his colleagues and friends. His skills and his caring personality will be missed by us all. BY BRIAN M. TWEEDLE

\section{HONOURS, AWARDS, APPOINTMENTS, AGMS}

BDA PEC election results

The BDA announced the results of elections to its Principal Executive Committee (PEC) in December. BDA members had to pick from 50 candidates. The unprecedented interest saw 44 members contest a single UK-wide seat.

Winners by constituency ( $\mathrm{n}=$ newly elected; $\mathrm{r}=$ re-elected):

Eastern - Jason Stokes (n)

N West - Stephen Shimberg (r)

Wales - Tim Harker (r)

West Midlands - Eddie Crouch (r)

- UK-wide - Len D’Cruz (n).

The PEC comprises 15 members in total. Annual renewal elections take place with a third of members up for election each year.

Facial aesthetics fellowship

Dr Nadine Skipp has been awarded a fellowship from the International Academy for Dental Facial Esthetics. Dr Skipp is Principal and Founder of AURA, the Centre of Dental Excellence and Facial Aesthetics in Kingston Upon Thames. The award, which was presented at the Greater New York Dental Meeting 2014, recognised the contribution that Dr Skipp has made to cosmetic and facial aesthetics.

New Year Honours

Thomas Raymond [Ray] Watkins, lately Consultant in Dental Public Health, NHS Grampian, has been made a Commander of the Order of the British Empire (CBE) in the New Year Honours for services to healthcare. Elizabeth Jones, Postgraduate Dental Dean for London, was named OBE for services to dental education, and Professor Jennifer Elizabeth Gallagher, Professor of Oral Health Strategy at King's College London, receives an OBE for services to oral health.

Gillian Davies, a specialist in Dental Public Health for Greater Manchester and the Dental Observatory, Public Health England, has been named MBE for services to dental public health. Shazad Saleem, a dentist at Glodwick Dental Practice in Oldham, receives the British Empire Medal (BEM) for services to dentistry.

Middlesex and Hertfordshire AGM

The Annual General Meeting of the Middlesex and Hertfordshire Branch of the BDA will be held on Thursday 5 February 2015 at the Holiday Inn, Elstree,WD6 5PU (M25 Junction 23) at 7 pm prompt. All members of the Branch are welcome to attend and vote. Apologies to Marion English on 01992460467 or 01707 332924/394613. In case of adverse weather conditions please contact 07515559716. 